\title{
Relationships between pazopanib exposure and clinical safety and efficacy in patients with advanced renal cell carcinoma
}

\author{
A B Suttle ${ }^{\star 1}$, H A Ball ${ }^{2}$, M Molimard ${ }^{3}$, T E Hutson ${ }^{4}$, C Carpenter $^{1,5}$, D Rajagopalan ${ }^{2}$, Y Lin ${ }^{2}, S_{\text {Swann }}^{2}$, \\ R Amado ${ }^{2}$ and L Pandite ${ }^{1}$ \\ ${ }^{1}$ Salix Pharmaceuticals, Inc., 8510 Colonnade Center Drive Raleigh, NC 27615, USA; ${ }^{2}$ GlaxoSmithKline, 1250 S. Collegeville Road, \\ Collegeville, PA 19426, USA; ${ }^{3}$ Pharmacology Department, Université de Bordeaux INSERM U657, 146 Leo Saignat, Bordeaux \\ 33076, France; ${ }^{4}$ GU Oncology Center of Excellence, Baylor University Medical Center, 3410 Worth Street, Dallas, TX 75246, USA \\ and ${ }^{5}$ GlaxoSmithKline, 5 Moore Drive, Research Triangle Park, NC 27709, USA
}

Background: Pazopanib, an oral angiogenesis inhibitor targeting vascular endothelial growth factor receptor (VEGFR)/plateletderived growth factor receptor (PDGFR)/c-Kit, is approved in locally advanced/metastatic renal cell carcinoma (RCC).

Methods: Data from trials in advanced solid tumours and advanced/metastatic RCC were used to explore the relationships between plasma pazopanib concentrations and biomarker changes, safety, and efficacy. Initially, the relationships between pharmacokinetic parameters and increased blood pressure were investigated, followed by analysis of steady-state trough concentration $(C \tau)$ and sVEGFR2, safety, progression-free survival (PFS), response rate, and tumour shrinkage. Efficacy/safety end points were compared at $C \tau$ decile boundaries.

Results: Strong correlation between increased blood pressure and $C \tau$ was observed $\left(r^{2}=0.91\right)$, whereas weak correlation was observed between $C \tau$ and decline from baseline in SVEGFR2 $\left(r^{2}=0.27\right)$. $C \tau$ threshold of $>20.5 \mu \mathrm{g} \mathrm{ml}^{-1}$ was associated with improved efficacy (PFS, $P<0.004$; tumour shrinkage, $P<0.001$ ), but there was no appreciable benefit in absolute PFS or tumour shrinkage from $C \tau>20.5 \mu \mathrm{g} \mathrm{ml}^{-1}$. However, the association of $C \tau$ with certain adverse events, particularly hand-foot syndrome, was continuous over the entire $C_{\tau}$ range.

Conclusions: The threshold concentration for efficacy overlaps with concentrations at which toxicity occurs, although some toxicities increase over the entire $C \tau$ range. Monitoring $C \tau$ may optimise systemic exposure to improve clinical benefit and decrease the risk of certain adverse events.

Pazopanib (Votrient, GlaxoSmithKline, Philadelphia, PA, USA) is an oral angiogenesis inhibitor targeting vascular endothelial growth factor receptors (VEGFR)-1, -2, and -3, platelet-derived growth factor receptors- $\alpha /-\beta$, and c-Kit (Kumar et al, 2007; Sonpavde et al, 2008). Pazopanib is approved in the United States (U.S. Department of Health and Human Services Food \& Drug Administration, 2009), European Union (European Medicines Agency, 2010), and other countries (Australian Government
Department of Health and Ageing, 2010; Instituto de Salud Publica de Chile, 2010; Kidney Cancer Canada, 2010) for the treatment of renal cell carcinoma (RCC). The efficacy and safety of pazopanib in treatment-naive and cytokine-pretreated patients with advanced/metastatic RCC was demonstrated in an open-label, single-arm Phase II trial (Hutson et al, 2010) and in a randomized, double-blind, placebo-controlled Phase III trial (Sternberg et al, 2010). In the Phase II study, patients treated with single-agent

*Correspondence: Dr AB Suttle; E-mail: Ben.Suttle@Salix.com

Previous Publication: Portions of the data were presented at the 2010 ASCO Annual Meeting (J Clin Oncol 28:15s, 2010, abstract 3048).

Received 7 May 2014; revised 29 July 2014; accepted 18 August 2014; published online 28 October 2014

(c) 2014 Cancer Research UK. All rights reserved 0007-0920/14 
pazopanib experienced an overall response rate of $35 \%$ and median progression-free survival (PFS) of 12 months (Hutson et al, 2010). In the Phase III study, pazopanib significantly improved PFS compared with placebo in the overall study population $(9.2 \mathrm{vs} 4.2$ months; hazard ratio 0.46; 95\% CI, 0.34-0.62; $P<0.0001$; Sternberg et al, 2010).

A number of factors affect the efficacy of a drug or treatment regimen in patients with cancer; these include patient and tumour characteristics, tumour biology, and systemic exposure to the drug. Among these, parameters of drug exposure are most amenable to regular monitoring, and may potentially provide insight towards dose optimisation. Emerging evidence corroborates the association of clinical and biologic effects of small-molecule tyrosine kinase inhibitors with the level of systemic exposure. For example, tumour response rates, time to progression, and overall survival were significantly better in patients with RCC who achieved a target threshold exposure to sunitinib plus its primary active metabolites (Houk et al, 2010). Similarly, clinical benefit is reduced when plasma concentrations of imatinib decrease to below $\sim 1000 \mathrm{ng} \mathrm{ml}^{-1}$ in patients with gastrointestinal stromal tumours or patients with chronic myeloid leukaemia (Eechoute et al, 2011).

In addition to the correlation with efficacy, systemic exposure of a drug may also correlate with biomarkers indicative of target inhibition. Administration of sunitinib results in changes in levels of circulating proteins associated with angiogenesis, including soluble VEGFR2 (sVEGFR2; Faivre et al, 2006; Motzer et al, 2006; Deprimo et al, 2007). The decrease in sVEGFR2 observed after administration of sunitinib in patients with RCC demonstrated a weak relationship with the steadystate trough plasma sunitinib concentrations (Deprimo et al, 2007). VEGFR2 is the predominant receptor that mediates production of nitric oxide and prostacyclin by endothelial cells, leading to vasodilation. Administration of VEGF in animals and humans causes vasodilation and decreases in blood pressure. In contrast, inhibition of VEGFR signalling increases blood pressure (Li et al, 2002; Janvier et al, 2005; Roodhart et al, 2008). Hypertension has been noted as a possible pharmacodynamic marker of anti-VEGF therapy, although its prognostic and predictive roles in the treatment of cancer are controversial (Scartozzi et al, 2009; Hurwitz et al, 2010; Rini, 2010). Thus, biomarkers of target inhibition such as sVEGFR2 and blood pressure may confirm inhibition of the targeted receptor and provide insight into the optimal dose of a therapeutic agent.

Preclinical studies have demonstrated that the inhibitory activity of pazopanib towards VEGFR2 phosphorylation, angiogenesis, and tumour growth is concentration dependent (Kumar et al, 2007; Harris et al, 2008). In these models, the in vivo activity of pazopanib required steady-state concentrations of at least $40 \mu \mathrm{M}$ $\left(17.5 \mu \mathrm{g} \mathrm{ml}^{-1}\right)$ during the entire dosing interval rather than transient maximal concentrations (Kumar et al, 2007). These results suggest that constant target inhibition during treatment is required to maximise the therapeutic effect of pazopanib in preclinical models of in vivo activity.

Accordingly, the present analyses were conducted to determine the pharmacokinetic and pharmacodynamic relationship between pazopanib and markers of clinical efficacy and safety. Markers of target engagement, blood pressure and sVEGFR2, and end points of safety and efficacy were examined to investigate the range of plasma pazopanib concentrations that could optimise benefit to patients with RCC.

\section{MATERIALS AND METHODS}

The initial analysis of the relationship between plasma pazopanib concentrations and increased blood pressure was conducted with data from patients with advanced solid tumours enroled in a firstin-human Phase I study (Hurwitz et al, 2009). That dose-escalation study provided individual hypertension data over a wide range of pazopanib concentrations; patients received pazopanib doses of 50 and $100 \mathrm{mg}$ three times weekly, 50-2000 mg once daily, and 300 and $400 \mathrm{mg}$ twice daily. Blood pressure and pharmacokinetic data were available for 54 of the 63 enroled patients.

Serial blood samples $(4 \mathrm{ml})$ were collected for determination of plasma pazopanib concentrations on days 1 and 22 in the Phase I study as described previously (Hurwitz et al, 2009). Plasma pazopanib area under the curve (AUC), maximum concentration $\left(C_{\max }\right)$, and trough concentrations $(C \tau)$ observed on study day 22 were included to investigate the pharmacokinetic and pharmacodynamic relationships between systemic exposure and increased blood pressure. $C \tau$ was defined as the plasma pazopanib concentration at $24 \mathrm{~h}$ after the first dose on day 22 in the oncedaily and twice-daily cohorts and as the predose concentration on day 22 in the three-times-weekly cohorts. AUC from 0 to $24 \mathrm{~h}$ after dosing was measured in the three-times-weekly and once-daily cohorts. AUC from 0 to $12 \mathrm{~h}$ after dosing was measured in the twice-daily dosing cohorts.

Blood pressure was measured in the Phase I study during clinic visits at baseline, on study days 8,15 , and 22, and every 3 weeks thereafter until the patient was withdrawn from the study. Patients also recorded blood pressure with a digital monitor at least twice daily at home between clinic visits, and all blood pressure data were included in the analysis. A significant increase in blood pressure was defined as a $15 \mathrm{~mm} \mathrm{Hg}$ or greater increase from baseline in the mean arterial blood pressure (MAP; calculated as $(2 \times$ diastolic pressure + systolic pressure)/3) on at least three separate occasions, initiation or escalation of antihypertensive medications, or both. The occurrence of a significant increase in blood pressure in a patient was described as a binomial response (yes or no). Only elevations in MAP or escalation of antihypertensive regimens that occurred while the patients remained on their initial starting dose of pazopanib were included in this analysis.

Patients were grouped according to the quintiles of each pharmacokinetic parameter (AUC, $C_{\max }, C \tau$ ). Quintiles of pharmacokinetic parameters were chosen to examine trends that may be obscured by the variability in the data. The proportion of patients who experienced a significant increase in blood pressure was determined within each quintile. A simple linear model was fit to the proportion of patients with increased blood pressure $v s$ the midpoint of the parameter quintile to investigate the correlation between each pharmacokinetic parameter and an increase in blood pressure. The correlation between AUC and $C \tau$ was also investigated.

Pharmacokinetics/pharmacodynamics in patients with RCC. The analysis of the relationship between plasma pazopanib concentrations and sVEGFR2, clinical efficacy, and safety in patients with RCC used data from 225 patients with locally advanced or metastatic RCC treated with pazopanib monotherapy in a single-arm Phase II trial (Hutson et al, 2010). The primary efficacy end point was overall response rate, and PFS was a secondary end point. Response was assessed by RECIST version 1.0 (Therasse et al, 2000) at week 12 and every 8 weeks thereafter. Serial blood samples $(2 \mathrm{ml})$ were collected at week 4 at the following times: predose (within $60 \mathrm{~min}$ before study drug administration; $C \tau)$ and $1-2 \mathrm{~h}, 3-4 \mathrm{~h}$, and $6-8 \mathrm{~h}$ post dose.

sVEGFR2. Plasma concentrations of sVEGFR2 were measured by enzyme-linked immunosorbent assay before initiation of treatment with pazopanib (baseline) and at 4, 8, and 12 weeks of pazopanib treatment. The post-baseline nadir (lowest concentration measured during the first 12 weeks) in plasma sVEGFR2 was identified for each patient, and the percent change from baseline in the 
sVEGFR2 concentration ( $\% \Delta$ sVEGFR2) was calculated as: $\% \triangle$ sVEGFR2 $=($ baseline - nadir $) /$ baseline $\times 100$.

Linear and nonlinear $\left(E_{\max }\right)$ models were used to describe the relationship between $\% \Delta$ sVEGFR2 and plasma pazopanib concentrations:

$$
\begin{gathered}
\% \Delta \text { sVEGFR2 }=\mathrm{INT}+\mathrm{SL} \times C \tau \\
\% \Delta \mathrm{sVEGFR} 2=E_{\max } \times C \tau /\left(\mathrm{EC}_{50}+C \tau\right)
\end{gathered}
$$

where $C \tau$ is the predose plasma pazopanib concentration at the week 4 visit, SL is the slope of the linear relationship between $C \tau$ and the decrease in sVEGFR2, INT is the intercept for the relationship, $E_{\max }$ is the maximum percent decrease from baseline for the sVEGFR2 nadir, and $\mathrm{EC}_{50}$ is the $C \tau$ at which the percent change from baseline for the sVEGFR2 nadir is 50\% of the maximum decrease. Models were fit to the data with $\mathrm{R}$ version 2.14.0 using the linear models or nonlinear least squares' packages. Model fits were compared by the Akaike information criteria.

Safety. Adverse events (AEs) from the Phase II study that occurred during the first 12 weeks of pazopanib treatment were used to explore concentration-effect relationships to allow sufficient time for the AEs to emerge and to minimise the confounding effects of factors that tend to increase over time on study, such as dose modifications, addition of concomitant medications, and disease progression. AEs were graded according to National Cancer Institute Common Terminology Criteria for Adverse Events (CTCAE) version 3.0. The incidence of all AEs was summarised according to the week 4 pazopanib $C \tau$ quartiles to allow for a sufficient number of events within each group to reveal concentration-related trends in the frequency. Statistical analyses of clinical efficacy data were conducted using SAS version 9.2 (SAS Institute, Inc., Cary, NC, USA).

Efficacy. Disease assessments were performed at week 12 of pazopanib treatment and every 8 weeks thereafter. The response rate was defined as the percentage of patients who achieved either a confirmed complete or partial response. A best response of stable disease required stable disease for at least 12 weeks after the first dose of pazopanib. Progression-free survival was defined as the interval between the first day of treatment and the earliest date of disease progression or death due to any cause, whichever occurred first.

The Phase II study originally was designed using randomized discontinuation design. All patients initially received pazopanib $800 \mathrm{mg}$ once daily for 12 weeks. After the week 12 disease assessment, patients with stable disease were randomized to receive pazopanib or placebo. After a planned interim analysis of safety and efficacy data, the design was amended to an open-label treatment where all patients received pazopanib $800 \mathrm{mg}$ once daily based on the recommendations of an independent data monitoring committee. Patients who were randomized to receive placebo $(n=28)$ were excluded from the pharmacokinetic/pharmacodynamic analysis; therefore, a total of 177 patients were included in the analysis of efficacy end points. Statistical analyses of clinical efficacy data were conducted with $\mathrm{R}$ version 2.14.0.

A PFS result was available for all patients included in the analysis, and sufficient data were available to group the results by pazopanib $C \tau$ at week 4 . After identifying the deciles of pazopanib $C \tau$ at week 4 , patients were split into two groups at each decile: those with a $C \tau$ concentration less than or equal to the decile boundary and those with a $C \tau$ concentration greater than the decile boundary. In the first analysis, the groups defined by the $C \tau$ deciles were used to determine a threshold value for $C \tau$ such that patients with $C \tau$ below this threshold had statistically significant worse PFS compared with patients with $C \tau$ above the threshold. In all, nine different values of $C \tau$ were examined. At each $C \tau$ decile tested, the PFS of patients in the two groups were compared using a log-rank test. The results were displayed graphically by plotting the log-rank $P$-value on the $y$ axis $v s$ each $C \tau$ decile border on the $x$ axis. The $C \tau$ that produced the lowest $P$-value for the comparison of PFS between groups was considered to be a threshold value for further analysis. Responses (complete response, partial response, stable disease, progressive disease, and not evaluable or unknown response) in the two groups defined by the $C \tau$ threshold were tested for independence using Fisher's exact test.

A similar analysis was conducted to identify a threshold value for $C \tau$ such that mean tumour reduction in patients with $C \tau$ below the threshold was significantly less than mean tumour shrinkage in patients with $C \tau$ above the threshold. The maximum tumour shrinkage based on the sum of the longest diameters of target lesions after the start of treatment was identified for each patient. The mean maximum post-baseline tumour shrinkage in patients with $C \tau$ above and below the deciles tested was compared using a $t$-test. No corrections for multiple testing were done in any analysis. All $P$-values reported are two sided with a significance level of 0.05 .

Once the $C \tau$ that yielded the most significant difference in PFS was identified, a Kaplan-Meier plot of the PFS for patients with $C \tau$ above and below the threshold was generated. An empirical cumulative distribution function of the maximum tumour shrinkage relative to baseline for patients with $C \tau$ values above and below the selected threshold value was constructed. For each group, these maximum tumour shrinkage values were ordered from largest to smallest tumour shrinkage post baseline, then plotted with the percentage of tumour shrinkage on the $x$ axis and the percentage of patients with at least that amount of tumour shrinkage on the $y$ axis.

Analyses were conducted to determine whether additional clinical benefit was observed at pazopanib $C \tau$ values greater than the week $4 C \tau$ decile threshold that resulted in the most significant difference in PFS and mean maximum post-dose tumour shrinkage. Data from patients with week $4 C \tau$ values below the threshold selected based on differences in PFS or mean maximum tumour reduction were removed. The analyses of PFS and tumour reduction described above were repeated at each remaining $C \tau$ decile boundary.

\section{RESULTS}

Blood pressure in patients with solid tumours. Plots of the occurrences of a significant increase in blood pressure $v s$ AUC, $C_{\max }$, and $C \tau$ are displayed in Figure 1A-C, respectively, for patients with solid tumours enroled in the Phase I study. The relationship between the occurrence of a significant increase in blood pressure and $C \tau$ yielded the largest $r^{2}$ value (0.91) and the lowest $P$-value $(0.0075)$ of the pharmacokinetic parameters. A significant relationship between AUC and $C \tau$ was observed $\left(r^{2}=0.63, P<0.001\right.$; Figure 1D).

Pharmacokinetics/pharmacodynamics in patients with advanced/ metastatic RCC. Predose plasma pazopanib concentrations at 4 weeks and AE data were available for 205 of the 225 patients (91\%) in the Phase II study. Longitudinal tumour size measurements sufficient to assess tumour shrinkage, and response rates were available from 197 patients (88\%). Plasma concentrations of sVEGFR2 and PFS data were available from 178 and 177 patients (79\%), respectively.

Efficacy. A summary of the PFS comparison at each week 4 pazopanib $C \tau$ decile is presented in Table 1 (see also Supplementary Figure S1). The week 4 plasma pazopanib $C \tau$ that yielded the most significant separation in median PFS was $17.4 \mu \mathrm{g} \mathrm{ml}^{-1}$. However, the greatest week $4 C \tau$ that yielded a significant separation in the median PFS was $20.5 \mu \mathrm{g} \mathrm{ml}^{-1}$. The week $4 C \tau$ boundaries of the 40 th percentile $\left(25.1 \mu \mathrm{g} \mathrm{ml}^{-1}\right)$ and greater did not result in a significant separation of the median PFS. 

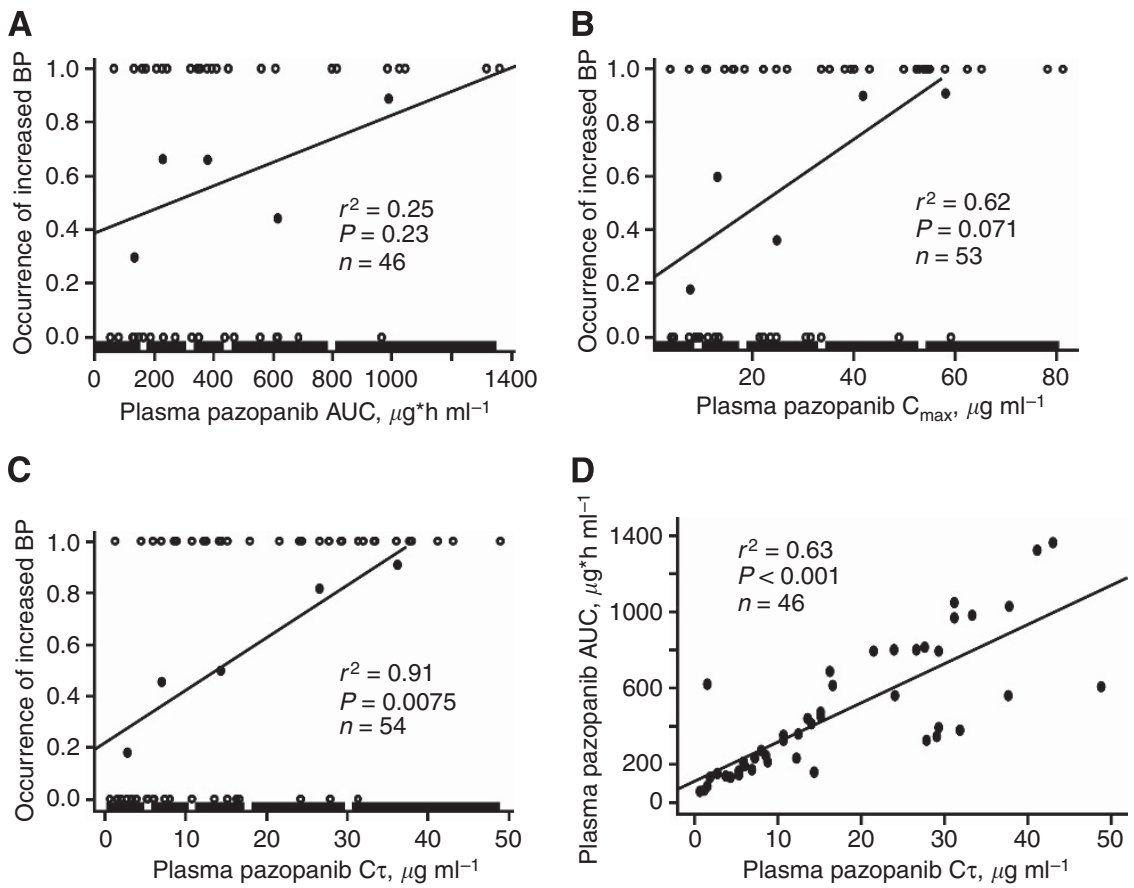

Figure 1. Pazopanib exposure and blood pressure. Relationship, in patients with solid tumours, between the occurrence of a significant increase in blood pressure (BP) and steady-state plasma pazopanib AUC (A), $C_{\max }(B)$, and $C \tau(C)$; relationship between steady-state $A U C$ and $C \tau(D)$. Open circles represent individual observations $(0=$ no significant increase; $1=$ significant increase) and closed circles represent the proportion of patients with a significant increase in blood pressure within each plasma pazopanib $C_{\tau}$ quintile range. The thick line represents the plasma pazopanib $C_{\tau}$ quintile range.

Table 1. Comparison of progression-free survival at each week 4 plasma pazopanib $C_{\tau}$ decile in the overall study population and in the subset of patients with $C_{\tau}$ above $20.5 \mu \mathrm{g} \mathrm{ml}^{-1}$

\begin{tabular}{|c|c|c|c|}
\hline & \multicolumn{2}{|c|}{ Median PFS, weeks (n) } & \multirow[b]{2}{*}{$\begin{array}{l}P \text {-value for } \\
\text { difference }\end{array}$} \\
\hline $\begin{array}{l}\text { Week } 4 \text { threshold, } \\
\mu \mathrm{g} \mathrm{ml}^{-1}\end{array}$ & $\begin{array}{l}\text { Above } \\
\text { threshold }\end{array}$ & $\begin{array}{l}\text { Below } \\
\text { threshold }\end{array}$ & \\
\hline \multicolumn{4}{|c|}{ Overall study population $(N=177)$} \\
\hline 12.5 & $43.7(159)$ & $20.3(18)$ & 0.035 \\
\hline 17.4 & 49.4 (141) & $13.9(36)$ & 0.00235 \\
\hline 20.5 & 52.0 (124) & $19.6(53)$ & 0.00378 \\
\hline 25.1 & $52.0(106)$ & $29.6(71)$ & 0.0529 \\
\hline 28.1 & 52.1 (88) & 29.6 (89) & 0.146 \\
\hline 31.15 & $53.0(71)$ & $35.3(106)$ & 0.252 \\
\hline 34.2 & $59.9(53)$ & 31.7 (124) & 0.115 \\
\hline 38.5 & $53.0(36)$ & $38.4(141)$ & 0.391 \\
\hline 47.6 & $49.4(18)$ & $39.3(159)$ & 0.609 \\
\hline \multicolumn{4}{|c|}{ Excluding patients with $C \tau \leqslant 20.5 \mu \mathrm{g} \mathrm{ml}^{-1}(n=124)$} \\
\hline 25.1 & $52.0(106)$ & $51.7(18)$ & 0.760 \\
\hline 28.1 & 52.1 (88) & $43.7(36)$ & 0.799 \\
\hline 31.1 & $53.0(71)$ & $43.7(53)$ & 0.779 \\
\hline 34.2 & 59.9 (53) & $39.3(71)$ & 0.519 \\
\hline 38.5 & $53.0(36)$ & 52.0 & 0.962 \\
\hline 47.6 & $49.4(18)$ & $52.0(106)$ & 0.940 \\
\hline
\end{tabular}

In the comparison of the median PFS of patients grouped by week $4 C \tau$ values, excluding patients with $C \tau \leqslant 20.5 \mu \mathrm{g} \mathrm{ml}^{-1}$ resulted in no statistically significant difference in median PFS at any $C \tau$ boundary.

The comparisons of mean maximum tumour reduction in patients with $C \tau$ above and below each decile concentration at week 4 are presented in Table 2 . The greatest difference in the mean maximum tumour reduction was observed at the week 4 plasma pazopanib $C \tau$ of $20.5 \mu \mathrm{g} \mathrm{ml}^{-1}$. Unlike PFS results, the difference in mean maximum tumour reduction was statistically significant for all $C \tau$ decile boundaries, except the 80th and 90th percentiles ( 38.5 and $47.6 \mu \mathrm{g} \mathrm{ml}^{-1}$, respectively). This was the result of including patients with $C \tau \leqslant 20.5 \mu \mathrm{g} \mathrm{ml}^{-1}$ because there were no statistically significant differences in the maximum tumour reduction between patients grouped by $C \tau$ decile values after exclusion of patients with week $4 C \tau \leqslant 20.5 \mu \mathrm{g} \mathrm{ml}^{-1}$ (Table 2).

The week $4 C \tau$ of $20.5 \mu \mathrm{g} \mathrm{ml}^{-1}$ was the greatest value that significantly discriminated median PFS and mean maximum tumour reduction. Therefore, the week $4 C \tau$ of $20.5 \mu \mathrm{g} \mathrm{ml}^{-1}$ was used as the threshold for further analyses. The Kaplan-Meier curves of PFS and the empirical distribution function of the change in tumour size for patients with a week $4 \mathrm{C \tau}$ $\leqslant 20.5 \mu \mathrm{g} \mathrm{ml}^{-1}$ and $C \tau$ above $20.5 \mu \mathrm{g} \mathrm{ml}^{-1}$ are displayed in Figure 2. The median PFS for patients with a week $4 C \tau$ $\leqslant 20.5 \mu \mathrm{g} \mathrm{ml}^{-1}$ was 19.6 weeks. In contrast, the median PFS for patients with a week $4 C \tau$ above $20.5 \mu \mathrm{g} \mathrm{ml}^{-1}$ was 52.0 weeks. Median observed tumour shrinkage in patients with a week $4 C \tau$ above $20.5 \mu \mathrm{g} \mathrm{ml}^{-1}$ (37.9\%) was more than five-fold greater than the median observed tumour shrinkage in patients with a week $4 C \tau \leqslant 20.5 \mu \mathrm{g} \mathrm{ml}^{-1}(6.9 \%)$.

The percentage of patients who experienced stable disease as their best response was $40 \%$ for those with a week $4 C \tau$ $\leqslant 20.5 \mu \mathrm{g} \mathrm{ml}^{-1}$ and those with a week $4 C \tau$ above $20.5 \mu \mathrm{g} \mathrm{ml}^{-1}$. However, the percentage of patients with a week $4 C \tau$ above $20.5 \mu \mathrm{g} \mathrm{ml}^{-1}$ who had a best response of partial or complete response was more than double that of patients with a week $4 \mathrm{C \tau}$ $\leqslant 20.5 \mu \mathrm{g} \mathrm{ml}^{-1}$ (45 and 19\%, respectively). Likewise, the percentage of patients with progressive disease was more than double when week $4 C \tau$ was $\leqslant 20.5 \mu \mathrm{g} \mathrm{ml}^{-1} \quad(38 \%)$ compared with patients with a week $4 C \tau$ above $20.5 \mu \mathrm{g} \mathrm{ml}^{-1}$ (11\%).

sVEGFR2. Plasma sVEGFR2 concentrations decreased at least $10 \%$ from the baseline value to the nadir in 167 of 178 patients (94\%) from whom data were available. The fit of the linear and 
$E_{\max }$ models to the percent change from baseline in sVEGFR2 nadir $v s$ plasma pazopanib concentration is displayed in Supplementary Figure S2. The correlation between plasma pazopanib concentrations and the maximum decrease in sVEGFR2 was weak using the linear model $\left(r^{2}=0.27\right)$. However, the linear model produced a slightly lower Akaike information criterion relative to the fit of the $E_{\max }$ model to the data (1415 vs 1417) suggesting a slightly better fit of the data.

Adverse events. A summary of the most common (total incidence $\geqslant 5 \%$ ) treatment-emergent AEs by plasma pazopanib concentration quartile is presented in Table 3 . The incidence of increased MAP, diarrhoea, hair colour change, alanine aminotransferase increase, stomatitis, and hand-foot syndrome increased as the plasma pazopanib concentrations increased, with the highest incidence occurring in the fourth $C \tau$ quartile. The highest incidence of CTCAE grade 3/4 hypertension occurred in the third

Table 2. Mean tumour shrinkage in patients at each week 4 plasma pazopanib $C_{\tau}$ decile in the overall study population and in the subset of patients with $C_{\tau}$ above $20.5 \mu \mathrm{g} \mathrm{ml}^{-1}$

\begin{tabular}{|c|c|c|c|c|}
\hline & \multicolumn{2}{|c|}{$\begin{array}{l}\text { Mean tumour } \\
\text { shrinkage, \% }\end{array}$} & & \\
\hline $\begin{array}{l}\text { Threshold } \\
\text { concentration, } \\
\mu \mathrm{g} \mathrm{ml}^{-1}\end{array}$ & $\begin{array}{c}\text { Above } \\
\text { threshold }\end{array}$ & $\begin{array}{c}\text { Below } \\
\text { threshold }\end{array}$ & Difference & $\begin{array}{c}\begin{array}{c}P \text {-value } \\
\text { for } \\
\text { difference }\end{array} \\
\text { differen }\end{array}$ \\
\hline \multicolumn{5}{|c|}{ Overall study population $(N=177)$} \\
\hline $\begin{array}{l}12.5 \\
17.4 \\
20.5 \\
25.1 \\
28.1 \\
31.15 \\
34.2 \\
38.5 \\
47.6\end{array}$ & $\begin{array}{l}-31.7 \\
-34.5 \\
-37.9 \\
-37.5 \\
-39.0 \\
-39.8 \\
-40.2 \\
-36.0 \\
-31.0\end{array}$ & $\begin{array}{c}-2.96 \\
-4.85 \\
-6.86 \\
-16.0 \\
-18.6 \\
-21.3 \\
-24.0 \\
-27.1 \\
-28.7\end{array}$ & $\begin{array}{r}28.7 \\
29.7 \\
31.0 \\
21.5 \\
14.9 \\
18.5 \\
16.2 \\
8.9 \\
2.3\end{array}$ & $\begin{aligned}<0.001 \\
<0.001 \\
<0.001 \\
<0.001 \\
<0.001 \\
<0.001 \\
0.0020 \\
0.136 \\
0.693\end{aligned}$ \\
\hline \multicolumn{5}{|c|}{ Excluding patients with $C \tau \leqslant 20.5 \mu \mathrm{g} \mathrm{ml}^{-1}(n=124)$} \\
\hline $\begin{array}{l}25.4 \\
28.1 \\
30.5 \\
33.7 \\
37.9 \\
47.3\end{array}$ & $\begin{array}{l}-37.5 \\
-39.0 \\
-39.7 \\
-40.2 \\
-36.0 \\
-31.2\end{array}$ & $\begin{array}{l}-40.5 \\
-35.2 \\
-35.4 \\
-36.2 \\
-38.7 \\
-39.2\end{array}$ & $\begin{array}{r}-3 \\
3.8 \\
4.3 \\
4.0 \\
-2.7 \\
-8.0\end{array}$ & $\begin{array}{l}0.581 \\
0.460 \\
0.381 \\
0.457 \\
0.654 \\
0.181\end{array}$ \\
\hline
\end{tabular}

A

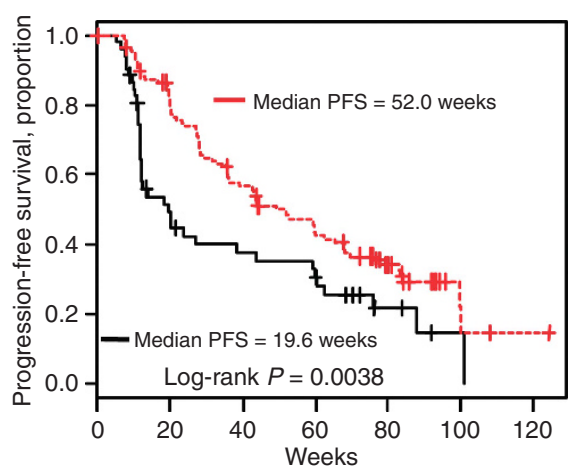

and fourth quartiles of $C \tau$. The increases in the incidences of hand-foot syndrome and MAP in the fourth quartile of $C \tau$ were the most marked. In contrast, the incidence of nausea, fatigue, vomiting, dysgeusia, and rash displayed no obvious relationship with pazopanib $C \tau$.

Pharmacokinetics. The mean and median $C \tau$ values on week 4 in the Phase II study were 28.8 and $28.1 \mu \mathrm{g} \mathrm{ml}^{-1}$, respectively (Figure 3). Dose reductions were allowed in this study. In all, 184 of the 205 patients with week $4 C \tau$ data received pazopanib $800 \mathrm{mg}$ once daily for at least 2 weeks; the mean week $4 C \tau$ value in those patients was $29.3 \mu \mathrm{g} \mathrm{ml}^{-1}$. For patients who experienced dose reductions or dose interruptions within 2 weeks of collection of the week 4 plasma sample, the mean week $4 C \tau$ value was $24.8 \mu \mathrm{g} \mathrm{ml}^{-1}$.

\section{DISCUSSION}

Results of the current analysis identified a threshold for pazopanib $C \tau$, which must be achieved for optimal efficacy in patients with

Table 3. Frequency of adverse events by week 4 pazopanib $C_{\tau}$ quartile $(n=205)$

\begin{tabular}{|c|c|c|c|c|}
\hline \multirow[b]{2}{*}{$\begin{array}{l}\text { Adverse events, all grades } \% \\
(\text { grade } 3 / 4)^{a}\end{array}$} & \multicolumn{4}{|c|}{$\begin{array}{l}\text { Pazopanib concentration range, } \\
\qquad \mu \mathrm{g} \mathrm{ml}^{-1}\end{array}$} \\
\hline & $\begin{array}{l}0.8 \text { to } \\
\leqslant 19\end{array}$ & $\begin{array}{l}>19 \text { to } \\
\leqslant 28\end{array}$ & $\begin{array}{l}28 \text { to } \\
\leqslant 36\end{array}$ & $\begin{array}{l}36 \text { to } \\
\leqslant 85\end{array}$ \\
\hline Hypertension $^{a}$ & $27(2)$ & $33(8)$ & $38(10)$ & $35(10)$ \\
\hline Increased MAP & 38 & 65 & 67 & 78 \\
\hline Diarrhoea & $24(0)$ & $49(0)$ & $65(0)$ & $67(2)$ \\
\hline Hair colour change & $18(0)$ & $37(0)$ & $37(0)$ & $51(0)$ \\
\hline Alanine aminotransferase increase & $8(4)$ & $14(6)$ & $15(12)$ & $16(4)$ \\
\hline Hand-foot syndrome & 0 & $4(2)$ & $6(0)$ & $24(6)$ \\
\hline Stomatitis & 0 & $4(0)$ & $2(0)$ & $10(0)$ \\
\hline Nausea & $35(2)$ & $37(0)$ & $31(2)$ & $41(0)$ \\
\hline Fatigue & $25(2)$ & $41(4)$ & $35(4)$ & $31(2)$ \\
\hline Vomiting & $14(0)$ & $14(0)$ & $13(2)$ & $18(0)$ \\
\hline Dysgeusia & $10(0)$ & $27(0)$ & $17(0)$ & $25(0)$ \\
\hline Rash & $10(2)$ & $10(0)$ & $15(0)$ & $8(2)$ \\
\hline \multicolumn{5}{|c|}{$\begin{array}{l}\text { Abbreviation: MAP }=\text { mean arterial blood pressure. } \\
{ }^{a} \text { Graded according to Common Terminology Criteria for Adverse Events (CTCAE; MAP was } \\
\text { not graded by CTCAE). } \\
\text { b } \\
\text { antihypertensive medications, or both. }\end{array}$} \\
\hline
\end{tabular}

B

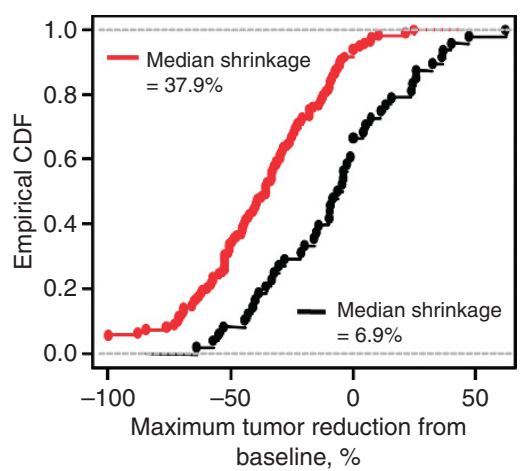

Week $4 \mathrm{c} \tau \leqslant 20.5 \mu \mathrm{g} \mathrm{ml}^{-1}$

Week $4 \mathrm{c} \tau>20.5 \mu \mathrm{g} \mathrm{ml}^{-1}$

Figure 2. Steady-state plasma pazopanib concentration and clinical response. The Kaplan-Meier curves showing PFS (A) and empirical cumulative distribution function (CDF) of maximum decrease from baseline in tumour size (B) for patients with week 4 predose steady-state plasma pazopanib concentration $(C \tau) \leqslant 20.5 \mu \mathrm{g} \mathrm{ml}^{-1}$ (black) and $>20.5 \mu \mathrm{g} \mathrm{ml}^{-1}$ (red). 


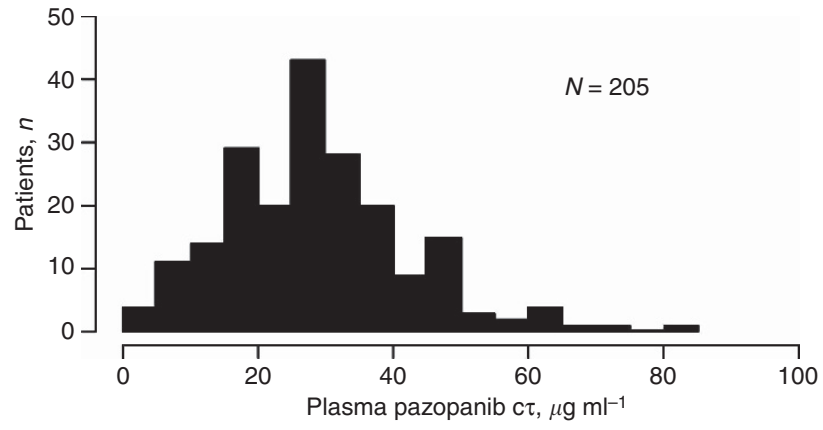

Figure 3. Distribution of predose steady-state plasma pazopanib concentrations $(C \tau)$.

RCC. This target pazopanib $C \tau$ is similar to the threshold steadystate concentration of at least $40 \mu \mathrm{M}\left(17.5 \mu \mathrm{g} \mathrm{ml}^{-1}\right)$ that was required for the inhibition of VEGF-induced VEGFR2 phosphorylation in mouse lungs. $C \tau$ measured immediately before pazopanib administration is assumed to be the lowest plasma concentration over the dosing interval. Therefore, these results suggest that maintenance of plasma pazopanib concentrations above $20.5 \mu \mathrm{g} \mathrm{ml}^{-1}$ for the entire dosing interval was associated with the most significant increases in PFS and tumour shrinkage. This hypothesis is supported by the observation that pazopanib $C \tau$ was better than $C_{\max }$ as a predictor of the occurrence of an increase in blood pressure in patients with solid tumours. Furthermore, Mancuso et al (2006) observed rapid vascular regrowth in a tumour cell line on interruption of VEGF inhibition, and Cacheux et al (2008) observed rapid regrowth of tumours in patients with metastatic colorectal cancer after interruption of bevacizumab therapy. In a study reported by Burstein (Burstein et al, 2008), levels of biomarkers of VEGFR inhibition (VEGF, sVEGFR2, sVEGFR3) were cyclical and coincident with the schedule of sunitinib used in the study ( 4 weeks on, 2 weeks off). Moreover, tumour growth of superficial cutaneous or nodal lesions was observed in several patients during the 2 -week period when no sunitinib was administered. Together, these results suggest that maintaining persistent suppression of the targeted signalling pathway may lead to better efficacy of these agents.

However, administration of sunitinib at the standard intermittent regimen of $50 \mathrm{mg}$ daily for 4 weeks followed by 2 weeks without treatment produced a numerically greater median PFS $v s$ $37.5 \mathrm{mg}$ daily administered on a continuous basis (8.5 vs 7.0 months; hazard ratio $0.77 ; P=0.070)$ in a randomized study in patients with advanced RCC (Motzer et al, 2012). The incidence and severity of AEs were similar between the continuous and intermittent regimens. These results suggest that the level of suppression of the target receptor achieved by administration of lower daily doses of sunitinib did not provide an advantage in clinical outcomes $v s$ intermittent administration of higher doses. Although alternative dosing regimens of pazopanib were not investigated in the present study, results suggest that the clinical benefit of pazopanib in RCC could be improved by increasing the proportion of patients with trough plasma pazopanib concentrations above a target threshold.

A concentration-dependent increase in the incidence of several AEs was also observed during the Phase II trial (Table 3; Supplementary Figure S3). Some toxicities such as hypertension and alanine aminotransferase elevations appeared to reach a plateau at higher concentrations. In contrast to hypertension, alanine aminotransferase elevations, and the results for measures of clinical efficacy, the incidence of diarrhoea, hand-foot syndrome, hair colour change, and stomatitis continued to increase as the trough plasma pazopanib concentration increased. There was no evidence of additional increases in PFS or tumour shrinkage if trough plasma pazopanib concentrations were maintained above threshold values $>20.5 \mu \mathrm{g} \mathrm{ml}^{-1}$. In addition to suggesting that escalation to a maximally tolerated dose of targeted agents such as pazopanib may not be necessary, these results reinforce the previous inference that increasing the dose of a targeted agent to a maximally tolerated level may only serve to affect the risk-tobenefit ratio negatively.

Dose reductions to $400 \mathrm{mg}$ pazopanib occurred in $\sim 30 \%$ of patients with RCC in the Phase II study. The most common AEs that led to dose interruptions or dose reductions were diarrhoea, hypertension, and increased ALT/AST (Hutson et al, 2010). All of those AEs demonstrated a concentration-dependent increase in frequency in the current analysis. Results suggest that the frequency of these common AEs could be reduced by decreasing systemic exposure to pazopanib through dose reductions or interruptions while maintaining plasma pazopanib concentrations above the threshold for optimal clinical effect in many patients.

The pazopanib dose of $800 \mathrm{mg}$ once daily was selected for Phase II and Phase III clinical trials based on target trough plasma concentrations that were associated with clinical and biologic effects in preclinical models and in patients with solid tumours (Kumar et al, 2007; Hurwitz et al, 2009). However, inter-patient heterogeneity in the metabolism and/or absorption of pazopanib can lead to differences in systemic exposure. Pazopanib is a Biopharmaceutics Classification System Class II drug, with high permeability and low solubility. The majority of an oral pazopanib dose is eliminated in the faeces, primarily as an unabsorbed drug, which is consistent with solubility-limited oral absorption. Pazopanib is a substrate of human p-glycoprotein (Pgp) and breast cancer resistance protein (BCRP; Deng et al, 2013). Differences in the expression of Pgp and BCRP may contribute to the intra-patient variability in systemic exposure to pazopanib after oral administration. Administration of esomeprazole in the evening and pazopanib in the morning resulted in 42 and $40 \%$ decreases in $C_{\max }$ and AUC, respectively (Tan et al, 2013). Administration of pazopanib with food increased $C_{\max }$ and AUC by approximately two-fold (Heath et al, 2010). Use of medications that alter gastric $\mathrm{pH}$ or administration in a partially fasted state also may contribute to the inter- and intra-patient variability of pazopanib pharmacokinetics.

In light of that variability and the relationship between systemic exposure and clinical benefit and toxicities, dose adjustments based on trough plasma concentrations may provide a method to optimise therapy with pazopanib by maintaining therapeutically effective blood levels, while minimising AEs whenever possible. Dose adjustment concurrent with therapeutic drug monitoring is widely used for compounds with a narrow therapeutic index, such as digoxin, antiepileptic agents, aminoglycosides, and immunosuppressants; this approach also has been recommended in certain situations for antiretroviral medications, where consistent target suppression is necessary (Pretorius et al, 2011). Use of a trough concentration may provide a convenient method of monitoring systemic exposure to pazopanib in a clinical setting, thereby allowing optimisation of the dosing regimen to gain maximum efficacy. Algorithms for therapeutic drug monitoring of tyrosine kinase inhibitors have been proposed (Haouala et al, 2009; Wang et al, 2009; Klumpen et al, 2011). Results from the present analysis indicate that plasma pazopanib concentrations obtained early (week 4) in the treatment period were predictors of effects consistent with VEGFR inhibition (increased blood pressure and decreases in sVEGFR2), clinical benefit, and the incidence of AEs. Recent improvements in bioanalytical detection have allowed the analysis of drug concentrations from small volumes $(<20 \mu \mathrm{l})$ of dried blood, making therapeutic monitoring of pazopanib concentrations in blood more feasible (Emmons and Rowland, 2010).

Further clinical studies are necessary to confirm the target threshold for pazopanib $C \tau$ and assess the effects of 
pharmacokinetics-guided dosing $v s$ standard pazopanib treatment. Strategies to optimise systemic exposure of pazopanib, such as dose escalation above $800 \mathrm{mg}$ once daily or administration of pazopanib with food in patients with concentrations below the target threshold, must be investigated in a prospective fashion in order for pharmacokinetics-guided dosing to be feasible. Finally, the safety and efficacy of pharmacokinetics-guided dosing relative to the standard dosing regimen for pazopanib should be determined in a randomized clinical trial.

\section{ACKNOWLEDGEMENTS}

We thank Jerome F Sah, PhD, ProEd Communications, Inc., for his medical editorial assistance with this manuscript. Financial support for this study (Study VEG105192; clinicaltrials.gov identifier NCT00334282) and medical editorial assistance was provided by GlaxoSmithKline Pharmaceuticals, Philadelphia, Pennsylvania.

\section{CONFLICT OF INTEREST}

CC, SS, RA, and LP are employees and stockholders of GlaxoSmithKline. ABS, HAB, YL, and DR are former employees of GlaxoSmithKline and hold company stock. MM has been a consultant or advisory board consultant for AstraZeneca, BristolMyers Squibb, GlaxoSmithKline, Mundipharma, Novartis, Stallergenes, and Pfizer. TEH has been a consultant, paid researcher, and participant in advisory boards or speaker's bureaus for Pfizer, GlaxoSmithKline, Novartis, AVEO, Johnson \& Johnson, and Dendreon.

\section{REFERENCES}

Australian Government Department of Health and Ageing (2010) Drugs designated as orphan drugs: Pazopanib (PATORMA). http://www.tga. gov.au/industry/pm-orphan-drugs.htm.

Burstein HJ, Elias AD, Rugo HS, Cobleigh MA, Wolff AC, Eisenberg PD, Lehman M, Adams BJ, Bello CL, DePrimo SE, Baum CM, Miller KD (2008) Phase II study of sunitinib malate, an oral multitargeted tyrosine kinase inhibitor, in patients with metastatic breast cancer previously treated with an anthracycline and a taxane. J Clin Oncol 26(11): $1810-1816$.

Cacheux W, Boisserie T, Staudacher L, Vignaux O, Dousset B, Soubrane O, Terris B, Mateus C, Chaussade S, Goldwasser F (2008) Reversible tumor growth acceleration following bevacizumab interruption in metastatic colorectal cancer patients scheduled for surgery. Ann Oncol 19(9): 1659-1661.

Deng Y, Sychterz C, Suttle AB, Dar MM, Bershas D, Negash K, Qian Y, Chen EP, Gorycki PD, Ho MY (2013) Bioavailability, metabolism and disposition of oral pazopanib in patients with advanced cancer. Xenobiotica 43(5): 443-453.

Deprimo SE, Bello CL, Smeraglia J, Baum CM, Spinella D, Rini BI, Michaelson MD, Motzer RJ (2007) Circulating protein biomarkers of pharmacodynamic activity of sunitinib in patients with metastatic renal cell carcinoma: modulation of VEGF and VEGF-related proteins. J Transl Med 5: 32.

Eechoute K, Sparreboom A, Burger H, Franke RM, Schiavon G, Verweij J, Loos WJ, Wiemer EA, Mathijssen RH (2011) Drug transporters and imatinib treatment: implications for clinical practice. Clin Cancer Res 17(3): 406-415.

Emmons G, Rowland M (2010) Pharmacokinetic considerations as to when to use dried blood spot sampling. Bioanalysis 2(11): 1791-1796.

European Medicines Agency (2010) Votrient (pazopanib) authorisation details. http://www.ema.europa.eu/ema/index.jsp?curl=pages/medicines/ human/medicines/001141/human_med_001337.jsp\&murl=menus/ medicines/medicines.jsp\&mid=WC0b01ac058001d124\&jsenabled=true.
Faivre S, Delbaldo C, Vera K, Robert C, Lozahic S, Lassau N, Bello C, Deprimo S, Brega N, Massimini G, Armand JP, Scigalla P, Raymond E (2006) Safety, pharmacokinetic, and antitumor activity of SU11248, a novel oral multitarget tyrosine kinase inhibitor, in patients with cancer. J Clin Oncol 24(1): 25-35.

Haouala A, Zanolari B, Rochat B, Montemurro M, Zaman K, Duchosal MA, Ris HB, Leyvraz S, Widmer N, Decosterd LA (2009) Therapeutic Drug Monitoring of the new targeted anticancer agents imatinib, nilotinib, dasatinib, sunitinib, sorafenib and lapatinib by LC tandem mass spectrometry. J Chromatogr B Analyt Technol Biomed Life Sci 877(22): 1982-1996.

Harris PA, Boloor A, Cheung M, Kumar R, Crosby RM, Davis-Ward RG, Epperly AH, Hinkle KW, Hunter 3rd RN, Johnson JH, Knick VB, Laudeman CP, Luttrell DK, Mook RA, Nolte RT, Rudolph SK, Szewczyk JR, Truesdale AT, Veal JM, Wang L, Stafford JA (2008) Discovery of 5-[[4-[(2,3-dimethyl-2H-indazol-6-yl)methylamino]-2pyrimidinyl]amino]-2-m ethyl-benzenesulfonamide (Pazopanib), a novel and potent vascular endothelial growth factor receptor inhibitor. J Med Chem 51(15): 4632-4640.

Heath EI, Chiorean EG, Sweeney CJ, Hodge JP, Lager JJ, Forman K, Malburg L, Arumugham T, Dar MM, Suttle AB, Gainer SD, LoRusso P (2010) A phase I study of the pharmacokinetic and safety profiles of oral pazopanib with a high-fat or low-fat meal in patients with advanced solid tumors. Clin Pharmacol Ther 88(6): 818-823.

Houk BE, Bello CL, Poland B, Rosen LS, Demetri GD, Motzer RJ (2010) Relationship between exposure to sunitinib and efficacy and tolerability endpoints in patients with cancer: results of a pharmacokinetic/ pharmacodynamic meta-analysis. Cancer Chemother Pharmacol 66(2): 357-371.

Hurwitz H, Douglas PS, Middleton JP, Sledge GW, Johnson DH, Reardon DA, Chen D, Rosen O (2010) Analysis of early hypertension (HTN) and clinical outcome with bevacizumab (BV). J Clin Oncol 28(15s): abstr 3039. Hurwitz HI, Dowlati A, Saini S, Savage S, Suttle AB, Gibson DM, Hodge JP, Merkle EM, Pandite L (2009) Phase I trial of pazopanib in patients with advanced cancer. Clin Cancer Res 15(12): 4220-4227.

Hutson TE, Davis ID, Machiels JP, De Souza PL, Rottey S, Hong BF, Epstein RJ, Baker KL, McCann L, Crofts T, Pandite L, Figlin RA (2010) Efficacy and safety of pazopanib in patients with metastatic renal cell carcinoma. J Clin Oncol 28(3): 475-480.

Instituto de Salud Publica de Chile (2010) Votrient coated tablets [product registration]. http://200.68.11.21/RegistrosISP/fiFichaProducto. asp?RegistroISP=F-18018/10.

Janvier A, Nadeau S, Baribeau J, Perreault T (2005) Role of vascular endothelial growth factor receptor 1 and vascular endothelial growth factor receptor 2 in the vasodilator response to vascular endothelial growth factor in the neonatal piglet lung. Crit Care Med 33(4): 860-866.

Kidney Cancer Canada (2010) Votrient (pazopanib) approved by Health Canada for the treatment of renal cell carcinoma. http://www.kidneycancercanada. org/main.php?p=600\&lan $=1$.

Klumpen HJ, Samer CF, Mathijssen RH, Schellens JH, Gurney H (2011) Moving towards dose individualization of tyrosine kinase inhibitors. Cancer Treat Rev 37(4): 251-260.

Kumar R, Knick VB, Rudolph SK, Johnson JH, Crosby RM, Crouthamel MC, Hopper TM, Miller CG, Harrington LE, Onori JA, Mullin RJ, Gilmer TM, Truesdale AT, Epperly AH, Boloor A, Stafford JA, Luttrell DK, Cheung M (2007) Pharmacokinetic-pharmacodynamic correlation from mouse to human with pazopanib, a multikinase angiogenesis inhibitor with potent antitumor and antiangiogenic activity. Mol Cancer Ther 6(7): 2012-2021.

Li B, Ogasawara AK, Yang R, Wei W, He GW, Zioncheck TF, Bunting S, de Vos AM, Jin H (2002) KDR (VEGF receptor 2) is the major mediator for the hypotensive effect of VEGF. Hypertension 39(6): 1095-1100.

Mancuso MR, Davis R, Norberg SM, O’Brien S, Sennino B, Nakahara T, Yao VJ, Inai T, Brooks P, Freimark B, Shalinsky DR, Hu-Lowe DD, McDonald DM (2006) Rapid vascular regrowth in tumors after reversal of VEGF inhibition. J Clin Invest 116(10): 2610-2621.

Motzer RJ, Hutson TE, Olsen MR, Hudes GR, Burke JM, Edenfield WJ, Wilding G, Agarwal N, Thompson JA, Cella D, Bello A, Korytowsky B, Yuan J, Valota O, Martell B, Hariharan S, Figlin RA (2012) Randomized phase II trial of sunitinib on an intermittent versus continuous dosing schedule as first-line therapy for advanced renal cell carcinoma. J Clin Oncol 30(12): 1371-1377.

Motzer RJ, Michaelson MD, Redman BG, Hudes GR, Wilding G, Figlin RA, Ginsberg MS, Kim ST, Baum CM, DePrimo SE, Li JZ, Bello CL, 
Theuer CP, George DJ, Rini BI (2006) Activity of SU11248, a multitargeted inhibitor of vascular endothelial growth factor receptor and platelet-derived growth factor receptor, in patients with metastatic renal cell carcinoma. J Clin Oncol 24(1): 16-24.

Pretorius E, Klinker H, Rosenkranz B (2011) The role of therapeutic drug monitoring in the management of patients with human immunodeficiency virus infection. Ther Drug Monit 33(3): 265-274.

Rini BI (2010) Biomarkers: hypertension following anti-angiogenesis therapy. Clin Adv Hematol Oncol 8(6): 415-416.

Roodhart JM, Langenberg MH, Witteveen E, Voest EE (2008) The molecular basis of class side effects due to treatment with inhibitors of the VEGF/VEGFR pathway. Curr Clin Pharmacol 3(2): 132-143.

Scartozzi M, Galizia E, Chiorrini S, Giampieri R, Berardi R, Pierantoni C, Cascinu S (2009) Arterial hypertension correlates with clinical outcome in colorectal cancer patients treated with first-line bevacizumab. Ann Oncol 20(2): $227-230$.

Sonpavde G, Hutson TE, Sternberg CN (2008) Pazopanib, a potent orally administered small-molecule multitargeted tyrosine kinase inhibitor for renal cell carcinoma. Expert Opin Investig Drugs 17(2): 253-261.

Sternberg CN, Davis ID, Mardiak J, Szczylik C, Lee E, Wagstaff J, Barrios CH, Salman P, Gladkov OA, Kavina A, Zarba JJ, Chen M, McCann L, Pandite L, Roychowdhury DF, Hawkins RE (2010) Pazopanib in locally advanced or metastatic renal cell carcinoma: results of a randomized phase III trial. J Clin Oncol 28(6): 1061-1068.
Tan AR, Gibbon DG, Stein MN, Lindquist D, Edenfield JW, Martin JC, Gregory C, Suttle AB, Tada H, Botbyl J, Stephenson JJ (2013) Effects of ketoconazole and esomeprazole on the pharmacokinetics of pazopanib in patients with solid tumors. Cancer Chemother Pharmacol 71(6): 1635-1643.

Therasse P, Arbuck SG, Eisenhauer EA, Wanders J, Kaplan RS, Rubinstein L, Verweij J, Van Glabbeke M, van Oosterom AT, Christian MC,

Gwyther SG (2000) New guidelines to evaluate the response to treatment in solid tumors. European Organization for Research and Treatment of Cancer, National Cancer Institute of the United States, National Cancer Institute of Canada. J Natl Cancer Inst 92(3): 205-216.

U.S. Department of Health and Human Services Food \& Drug Administration (2009) Pazopanib [approval notice] (http://www.fda.gov/AboutFDA/ CentersOffices/CDER/ucm187509.htm).

Wang Y, Chia YL, Nedelman J, Schran H, Mahon FX, Molimard M (2009) A therapeutic drug monitoring algorithm for refining the imatinib trough level obtained at different sampling times. Ther Drug Monit 31(5): 579-584.

This work is published under the standard license to publish agreement. After 12 months the work will become freely available and the license terms will switch to a Creative Commons AttributionNonCommercial-Share Alike 3.0 Unported License.

Supplementary Information accompanies this paper on British Journal of Cancer website (http://www.nature.com/bjc) 